\title{
Small-scale ontogenetic and diel vertical distributions of neritic copepods in Maizuru Bay, Japan
}

\author{
Hiroshi Ueda \\ Department of Marine Sciences, University of the Ryukyus, Nishihara, Okinawa 903-01, Japan
}

\begin{abstract}
Ontogenetic and diel vertical distributions of the dominant copepods Oithona davisae Acartia spp. (A. hudsonica and A. omorii) and Paracalanus crassirostris were studied in Maizuru Bay, middle Japan. A consistent ontogenetic pattern was found during daytime for all the species: mean distribution depths moved upwards with later naupliar stages and downwards during copepodite development. Details of this pattern vary with the species. Vertical distribution of $P$. crassirostris eggs is similar to that of the 1st naupliar stage (N1), while in Acartia egg distribution depends on adult females; Acartia N1 is always concentrated in water close to the bottom independent of egg distribution. This indicates that $P$. crassirostris eggs may drift until hatching while most Acartia eggs sink to the bottom before hatching. The ontogenetic distributional pattern observed in the daytime is generally obscured at night due to stage-specific nocturnal migrations.
\end{abstract}

\section{INTRODUCTION}

Ontogenetic vertical distributions of many planktonic copepods have been studied in cold oceanic waters; e.g. Calanus finmarchicus (Gunner), C. hyperboreus Krøyer, C. helgolandicus (Claus), C. cristatus Krøyer, C. plumchrus Marukawa, and Eucalanus bungii bungii Johnson exhibit ontogenetic migration in such waters (Banse 1964, Sekiguchi 1975, Williams \& Conway 1984). Their large scale (usually $>100 \mathrm{~m}$ ), seasonal, vertical migration is a part of their annual life history patterns. Similar studies in other marine areas have been relatively limited. In estuarine and inlet waters, in spite of knowledge about seasonal occurrence and population dynamics, studies of ontogenetic vertical distributions have been impeded by lack of information about egg and naupliar stages.

In 1978, the vertical distribution of copepods was investigated in Maizuru Bay, an inlet of Wakasa Bay on the Japan Sea coast of middle Japan (Fig. 1), where the planktonic fauna is dominated by a small number of neritic copepods. Oithona davisae Ferrari \& Orsi was the most abundant copepod throughout the year and extremely abundant from June to September, when the density of the copepodites usually exceeded $100 \mathrm{l}^{-1}$ in surface water. Acartia hudsonica Pinhey and A. omorii Bradford were dominant from March to May, and Paracalanus crassirostris Dahl from August to October. In the northwest Pacific, both Acartia species were attributed to $A$. clausi Giesbrecht until recently (Ueda 1986). In total these species comprised $>80 \%$ of the

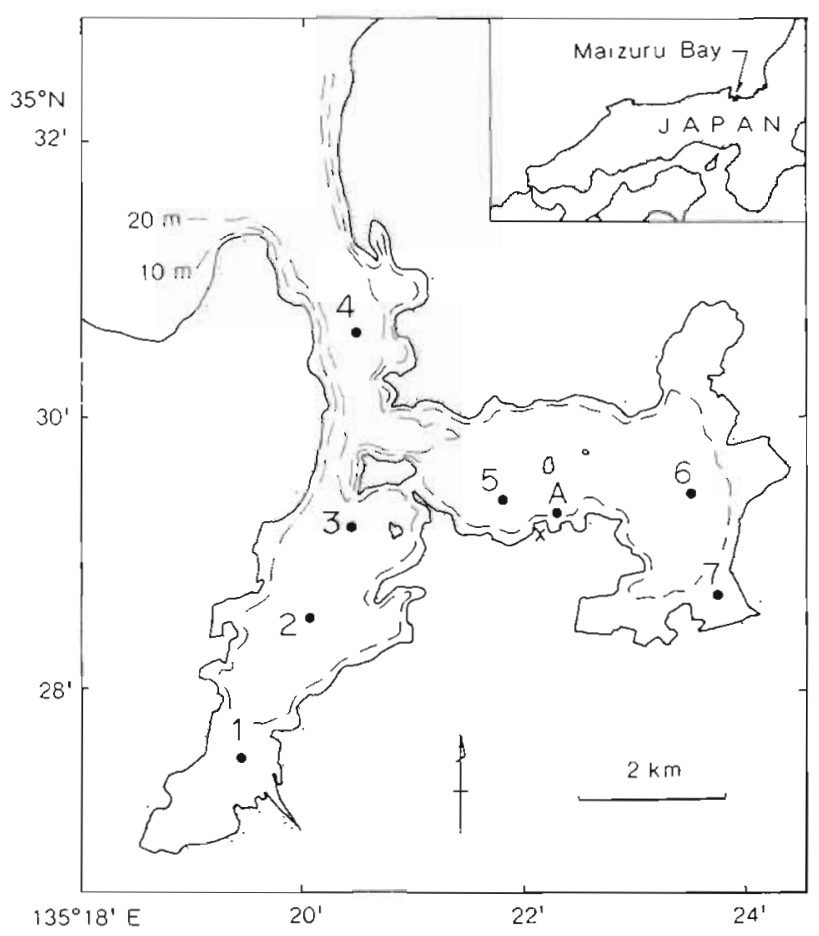

Fig. 1. Map of Maizuru Bay with station locations. $\times$ : location of the Fisheries Research Station, Kyoto University 
copepod population in the bay throughout the year. Here I describe vertical distribution of their developmental stages along with dicl changes in the distributions; particular attention is paid to egg and stagespecific naupliar distributions.

\section{MATERIAL AND METHODS}

Zooplankton were collected monthly at 7 stations (Stns 1 to 7, Fig. 1) in Maizuru Bay from January to December 1978. Sampling was made between 0930 and $1500 \mathrm{~h}$. At each station, $10 \mathrm{l}$ of seawater was sampled with a Van Dorn bottle at $5 \mathrm{~m}$ depth intervals from the surface to the bottom and immediately strained on board with a $25 \mu \mathrm{m}$ meshed net. Preliminary examinations indicated that $25 \mu \mathrm{m}$ mesh is sufficient for catching eggs and early naupliar stages of abundant smallsize dominant copepods in the bay. Diel vertical migration of copepods was studied at $\operatorname{Stn} A$, about $13 \mathrm{~m}$ deep, near the Fisheries Research Station, Kyoto University, on 29-30 March and 19-20 October, 1978. On each pair of days, samples were taken 6 times at 3 or $4 \mathrm{~h}$ intervals by the above method except that samplings were made at $2.5 \mathrm{~m}$ depth intervals from the surface to $12.5 \mathrm{~m}$. Sampling at each time was com-

surtace to 12.5 m. Sampling at

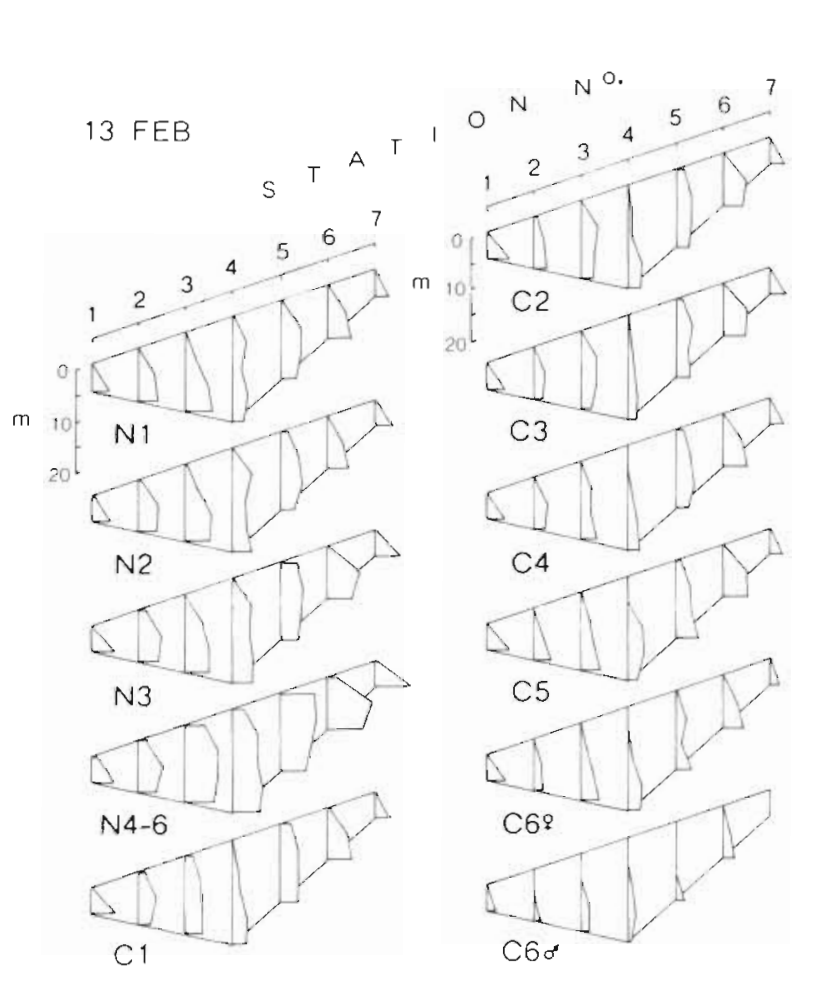

pleted within $25 \mathrm{~min}$. Temperature and salinity at Stn A were measured at $1 \mathrm{~m}$ depth intervals with an electronic temperature-salinity meter (Tsurumi-seiki Co. Ltd.) on 29-30 March and at $2.5 \mathrm{~m}$ depth intervals with a hand-held thermometer and electronic salinometer on 19-20 October.

All developmental stages, including eggs, of the aforementioned species were counted in $1 / 2$ subsamples or, for extremely abundant stages, in smaller subsamples. With the exceptions of $C 5$ and $C 6$ (adult) it was impossible to distinguish Acartia hudsonica and A. omorii because of their close similarity, and so the 2 species were not separated in the present study. Adults of $A$. omorii were generally more abundant in the mouth of the bay and replaced toward the innermost part by $A$. hudsonica (Ueda in press). Instars of late naupliar stages (N4 to N6) of Oithona davisae were not separated due to their similarity. Sexes of Acartia and Paracalanus crassirostris were distinguished in the stages from $\mathrm{C} 4$ to $\mathrm{C} 6$, but those of $O$. davisae were separated only in C6. Acartia and P. crassirostris spawn eggs freely in water and their eggs were identified by comparison to those spawned by conspecific females in laboratory. Egg sacs of $O$. davisae were counted whether they were attached to females or isolated. Since a gravid cyclopoid female carries $2 \mathrm{egg}$

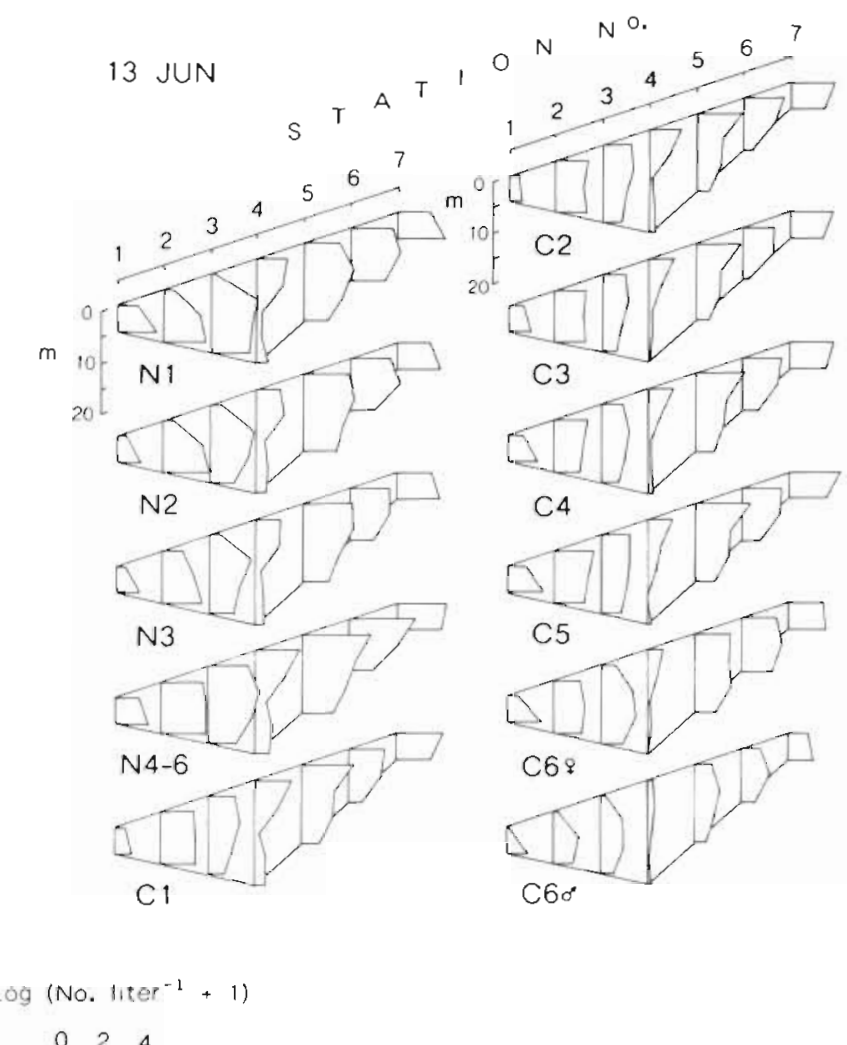

Fig. 2. Oithona davisae. Daytime vertical and horizontal distributions of each developmental stage and sex in Maizuru Bay on 13 Feb (left) and 13 Jun 1978 (right) 
(a) $17 \mathrm{APR}$
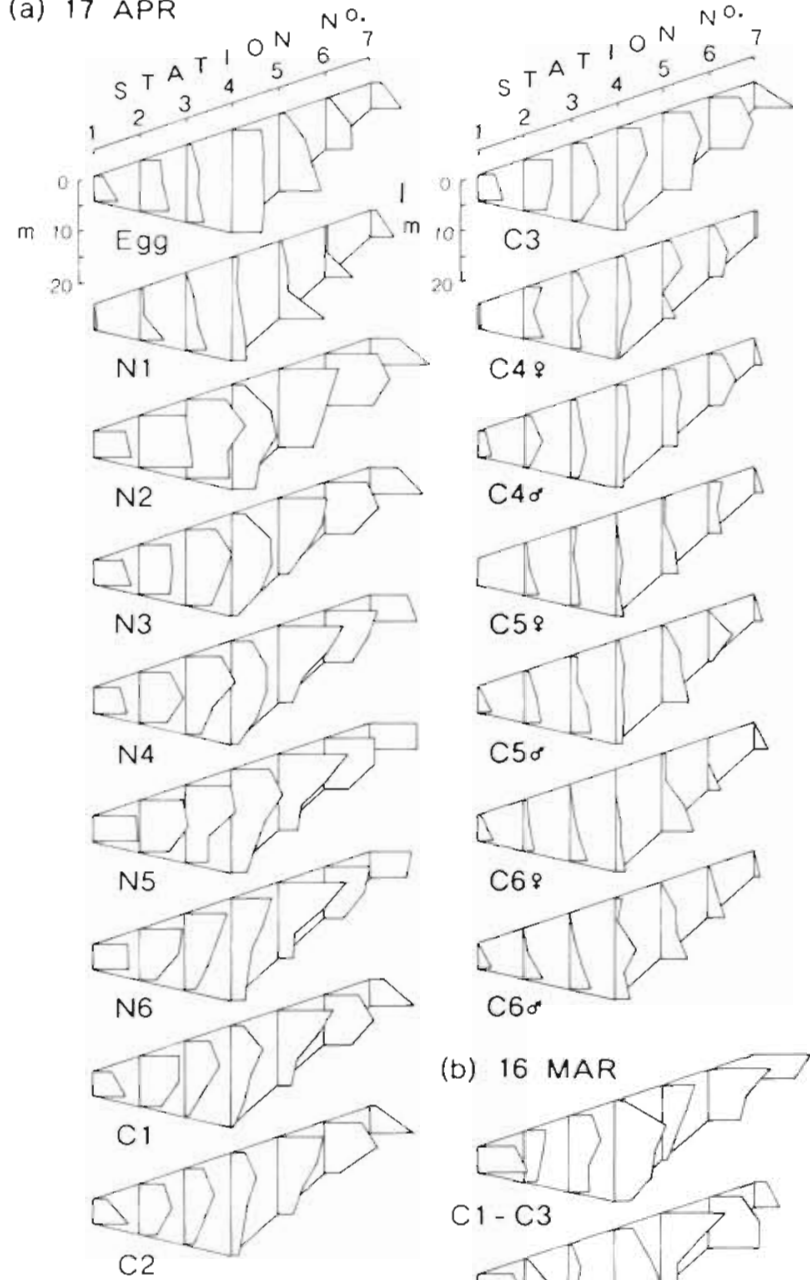

Log (No. liter $\left.{ }^{-1}+1\right)$

$0 \quad 12$

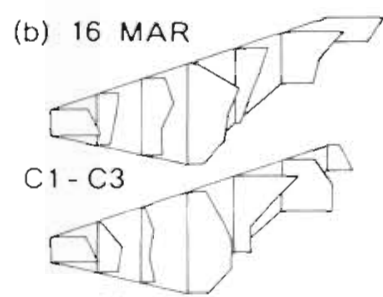

$\mathrm{C} 4-\mathrm{C} 6$

Fig. 3. Acartia spp. Daytime vertical and horizontal distributions of (a) each developmental stage and sex in Maizuru Bay on $17 \mathrm{Apr}$, and (b) early and late copepodite stages on $16 \mathrm{Mar}$ 1978

sacs until hatching, isolated egg sacs were considered to have dropped off after sampling and therefore a half of the total number of attached and isolated egg sacs was regarded as corresponding to the number of ovigerous females.

\section{RESULTS}

\section{Daytime ontogenetic vertical distribution}

Vertical and horizontal distributions of developmental stages of the dominant copepods during the daytime are shown in Fig. 2 to 4 . In these figures numerical abundances are expressed in log-transformed scale $\left[\log (N+1)\right.$, where $N=$ number $\left.l^{-1}\right]$ because the abundances varied greatly (100-fold or more) with sampling station and depth. Vertical distributions of Oithona davisae varied seasonally. In February, when copepod density was low, early naupliar stages were almost restricted to the mid and bottom layers, while late naupliar stages were scattered throughout the water column (Fig. 2). Copepodites older than C1 almost entirely avoided the surface layer. In June, when the species was extremely abundant in the bay, both nauplii and copepodites were generally more abundant in the top $5 \mathrm{~m}$. Early naupliar stages occurred more abundantly at the $5 \mathrm{~m}$ depth, except at Stn 2 , while the highest abundance of the older nauplii and immature copepodites were found at the surface. At Stn 2 the populations of early naupliar stages were centered at the $10 \mathrm{~m}$ depth and immature copepodite stages were at the surface. Adult copepods were generally most abundant at $5 \mathrm{~m}$ or $10 \mathrm{~m}$. Thus old nauplii and imma-

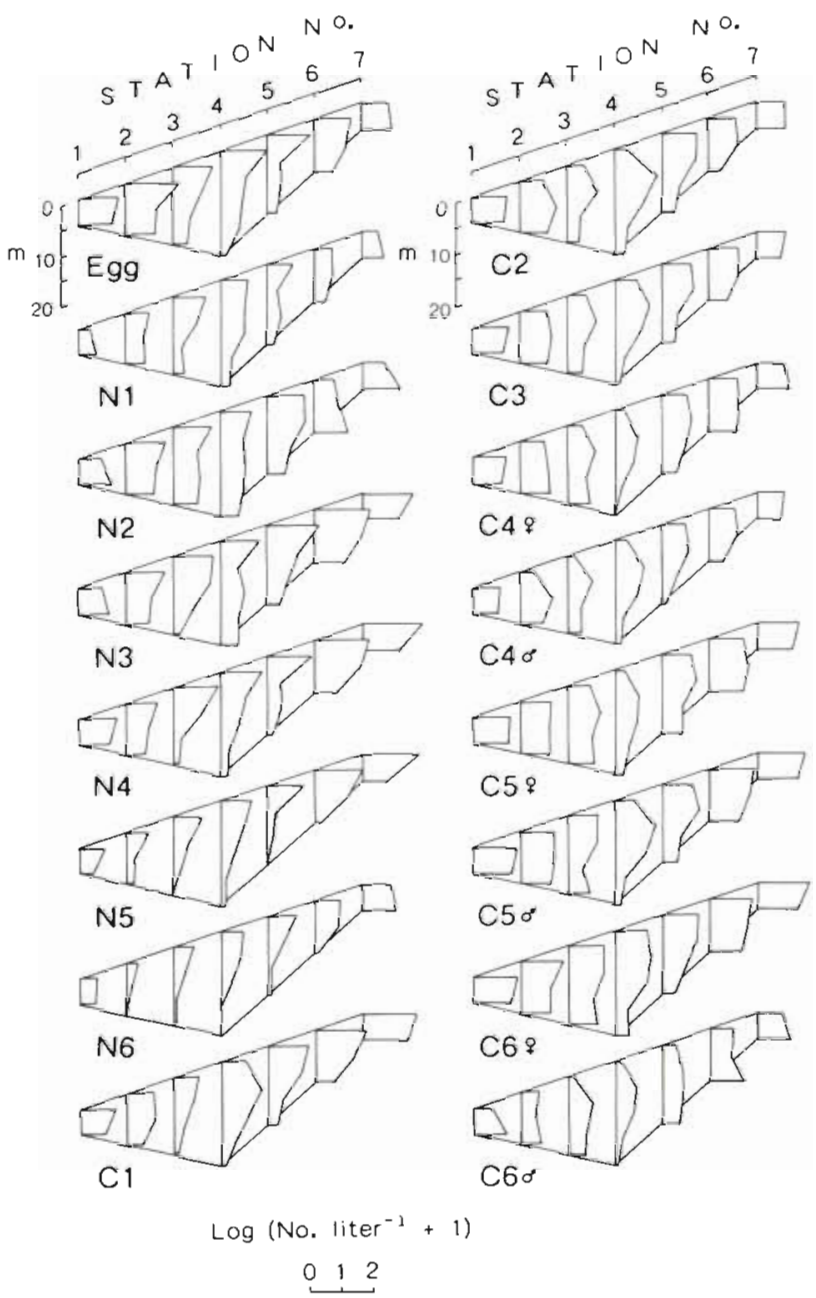

Fig. 4. Paracalanus crassirostris. Daytime vertical and horizontal distributions of each developmental stage and sex in Maizuru Bay on 19 Sep 1978 


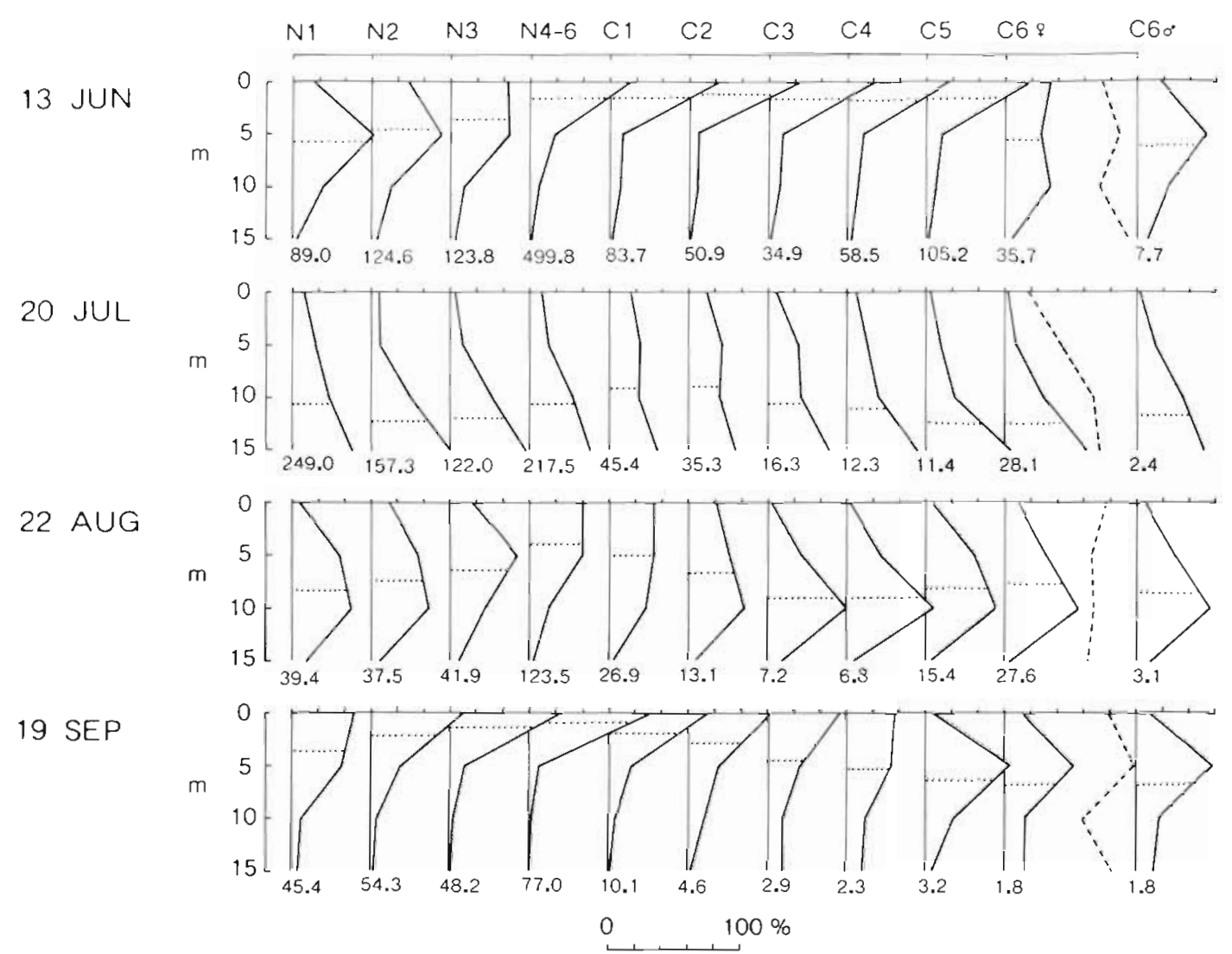

Fig. 5. Oithona davisae. Daytime ontogenetic vertical distributions at Stn 5 from Jun to Sep 1978. Vertical profiles represent relative abundance among the 4 sampling depths $\left(0,5,10\right.$ and $15 \mathrm{~m}$ ); mean abundance (no. $1^{-1}$ ) is noted under each profile. Horizontal dotted lines indicate mean distribution depths, which were calculated by $\Sigma(\mathrm{d} \times \mathrm{n}) / \Sigma \mathrm{n}$, where $\mathrm{d}=\mathrm{sampling}$ depth; $n=$ numerical abundance at the depth. Broken lines in the diagrams for C6? indicate vertical profiles of percentage of ovigerous females

$\begin{array}{llllllllllllllll}\text { Egg } & \mathrm{N} 1 & \mathrm{~N} 2 & \mathrm{~N} 3 & \mathrm{~N} 4 & \mathrm{~N} 5 & \mathrm{~N} 6 & \mathrm{C} 1 & \mathrm{C} 2 & \mathrm{C} 3 & \mathrm{C} 49 & \mathrm{C} 40^{\circ} & \mathrm{C} 59^{9} & \mathrm{C} 50^{\circ} & \mathrm{C6} & \mathrm{C} 60^{\circ}\end{array}$

16 MAR

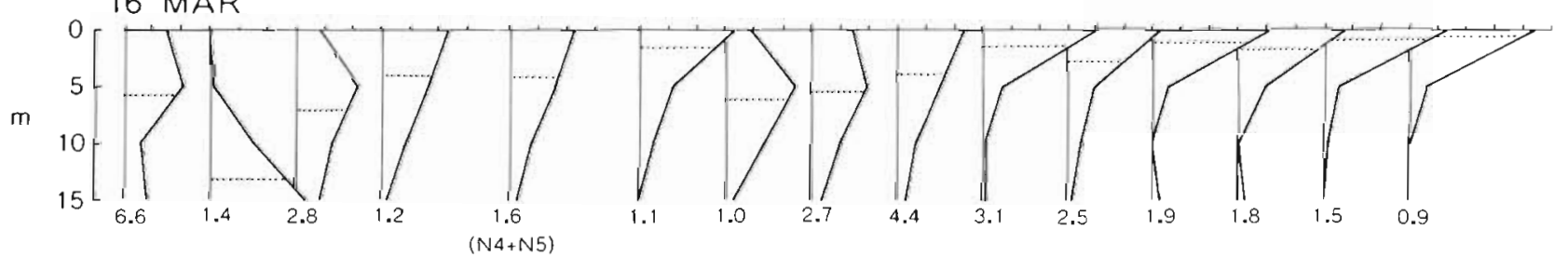

17 APR

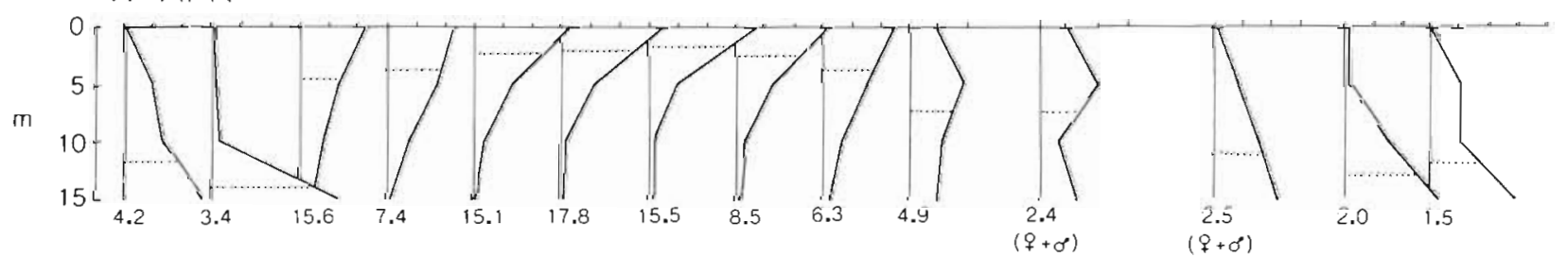

24 MAY
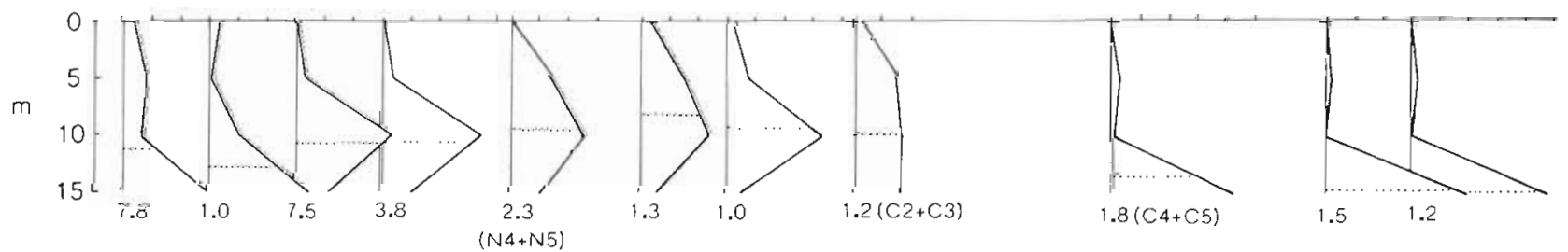

0 $100 \%$

Fig. 6. Acartia spp. Daytime ontogenetic vertical distributions at Stn 5 from Mar to May 1978. The stages and sexes of which mean abundances were $<11^{-1}$, except for $\mathrm{C} 60^{*}$, are combined with the neighboring stage or the other sex. For further explanation see legend to Fig. 5 

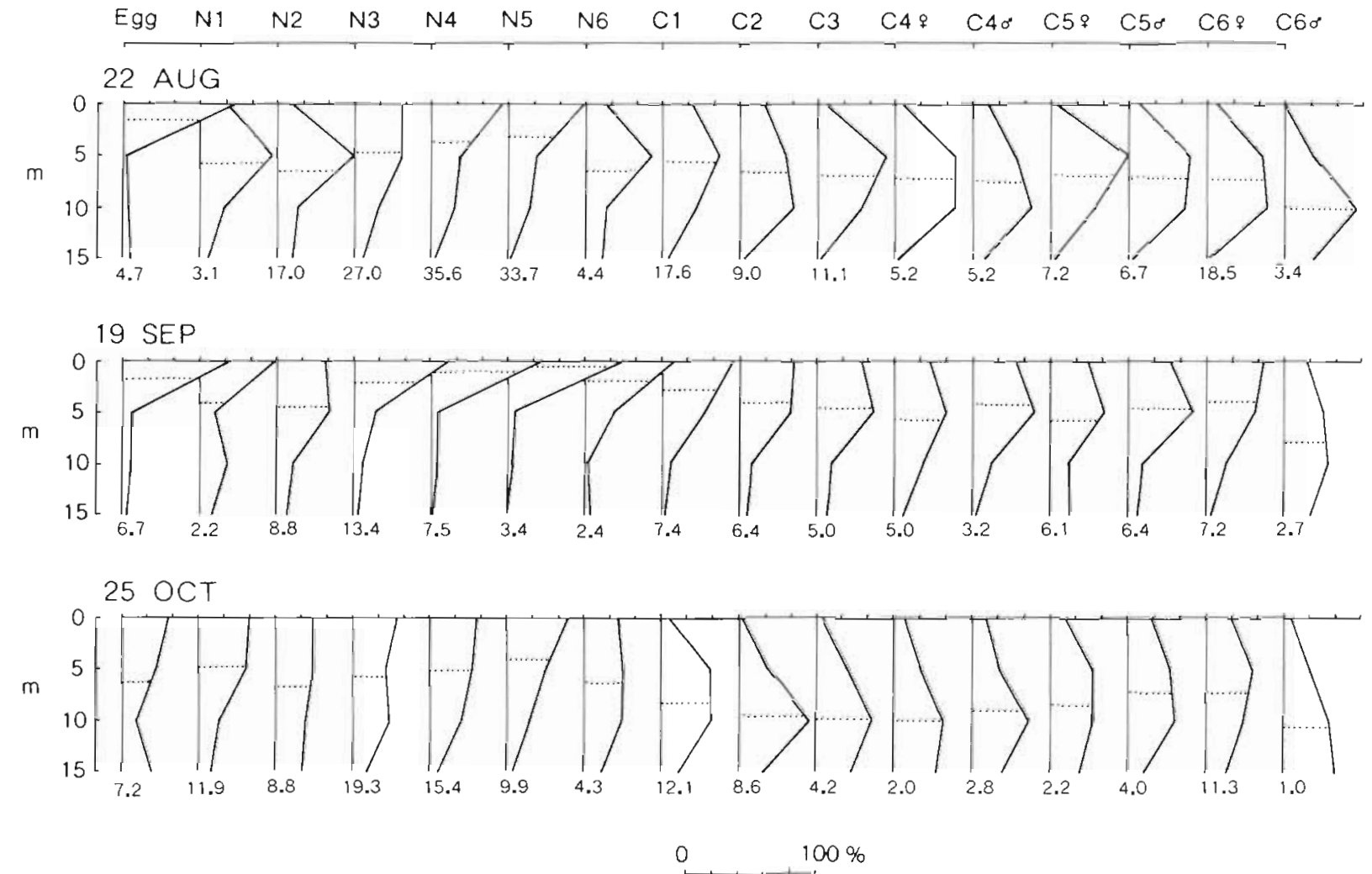

Fig. 7. Paracalanus crassirostris. Daytime ontogenetic vertical distributions at Stn 5 from Aug to Oct 1978. For further explanation see legend to Fig. 5
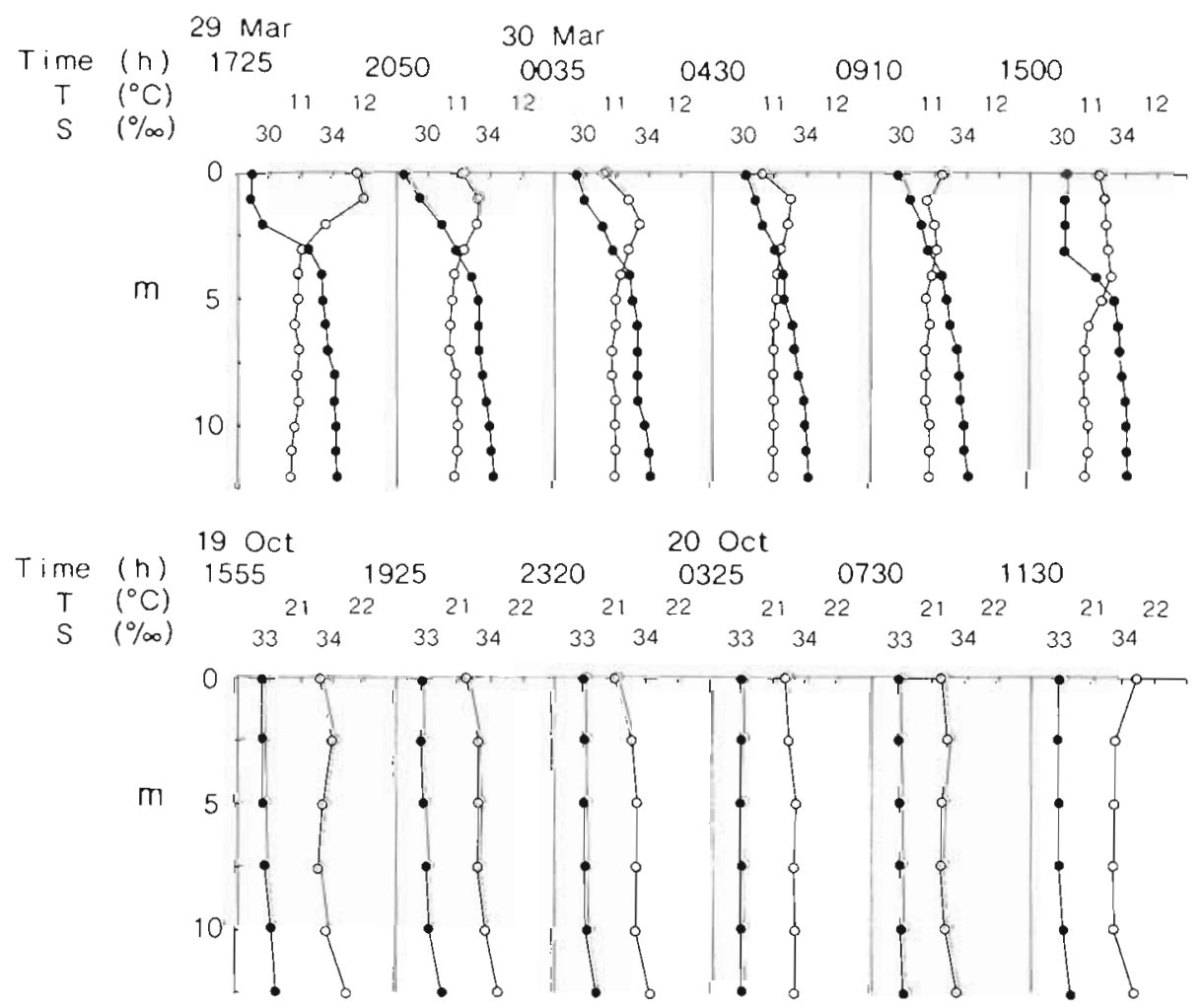

Fig. 8. Vertical profiles of temperature (0) and salinity (-) at Stn $A$ on 29-30 Mar (top) and 19-20 Oct 1978 (bottom) 


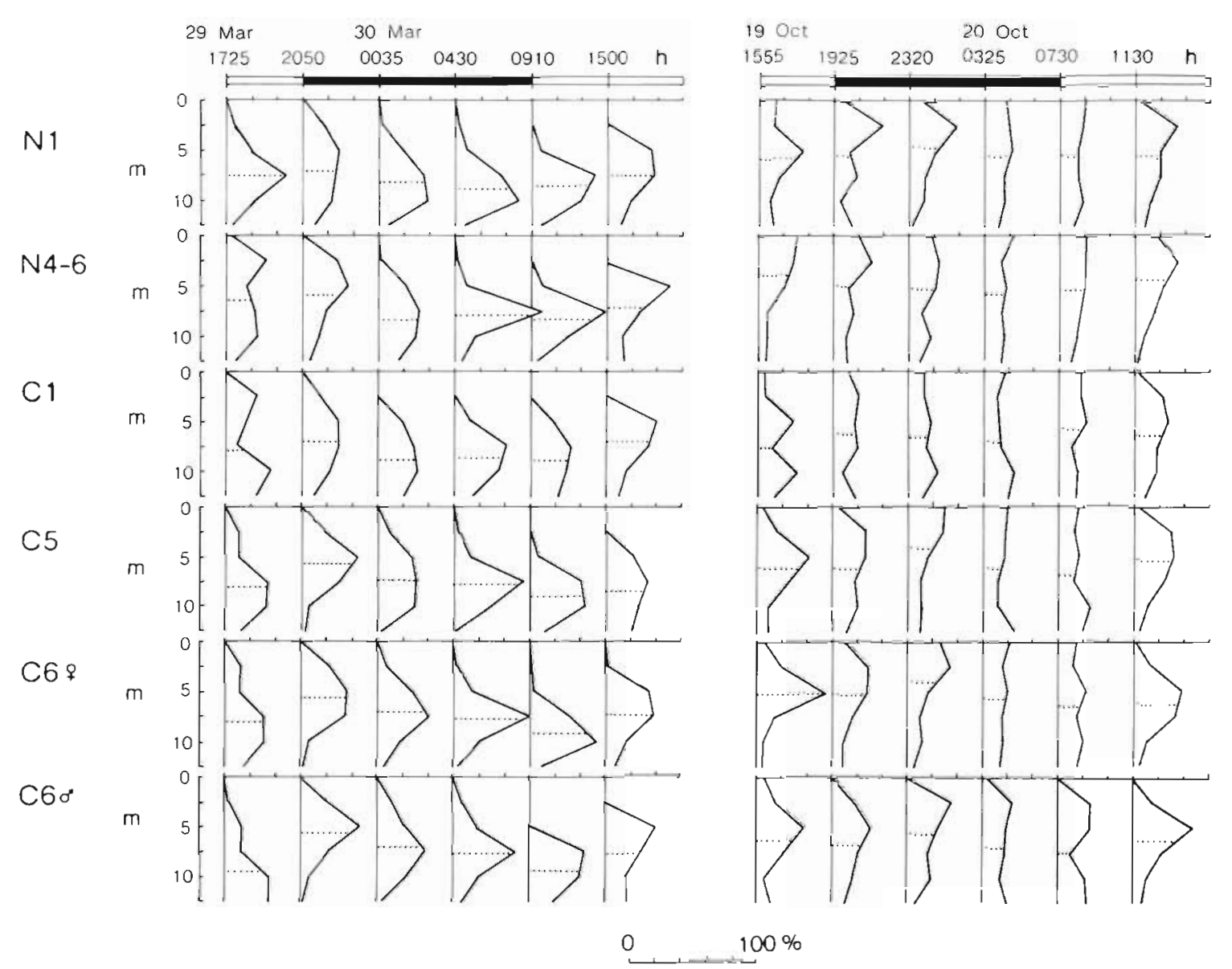

Fig. 9. Oithona davisae. Diel vertical distributions of given stages at Stn A on 29-30 Mar (left) and 19-20 Oct 1978 (right). Time noted above the figure is the hour when sampling was started. Sunset and sunrise at Maizuru Bay on 29 to 30 Mar, respectively, were at 1817 and $0549 \mathrm{~h}$; those on $19-29$ Oct at 1719 and $0608 \mathrm{~h}$. For further explanation see legend to Fig. 5

ture copepodites generally occupied shallower layers than younger nauplii and adult copepods.

Daytime ontogenetic patterns in vertical distribution of Acartia species were more pronounced than Oithona davisae. In April, for example, Acartia N1 was found in the bottom water throughout the bay and, in contrast, N6 was most abundant in the surface layer (Fig. 3a). After metamorphosis, the copepodites were found progressively deeper, and the adult stage was generally more abundant in the bottom layer. Eggs usually were more abundant at the bottom than at the surface except in the mouth of the bay (Stn 4). There were no consistent sexual differences in vertical distribution of Acartia late copepodites.

Paracalanus crassirostris also exhibited similar ontogenetic patterns, although not as striking as Acartia. In September, for example, the $P$. crassirostris population generally was concentrated at the surface or $5 \mathrm{~m}$ (Fig. 4). Eggs and nauplii were usually more abundant at the surface; early naupliar stages were more evenly scattered in the water column than the late stages. Copepodites older than $\mathrm{C} 1$ were found more often at $5 \mathrm{~m}$. In $\mathrm{C} 4$ and $\mathrm{C} 5$, vertical distributions did not markedly differ between the sexes, but the highest abundance of adult males was generally found in deeper waters than adult females.

For the purpose of detailed stage-by-stage comparison, vertical distribution as expressed by relative abundances among the sampling layers, and mean distribution depth of each developmental stage at Stn 5 during periods of high abundance, are shown in Fig. 5 to 7 . These figures indicate that relative abundances in the higher waters generally increased during naupliar development and that a reverse trend for progressively older copepodite stages was a common pattern for all the species. However, details of the changes varied with the species and month. The mean distribution depth of Oithona davisae was the highest for $\mathrm{C} 2$ in June and July, although the differences in the mean depth between the successive stages from N4 to 6 up to C5 were not statistically significant ( $p>0.05$, t-test) in June (Fig. 5). In August and September, on the other 


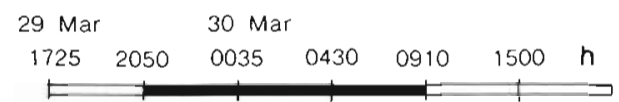

Egg

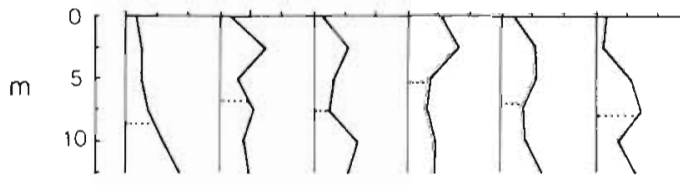

N1

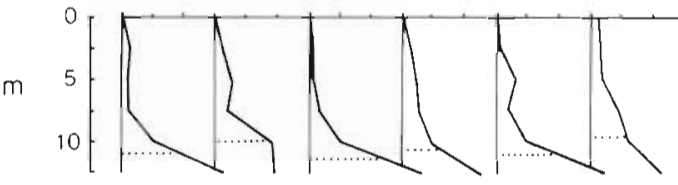

N6

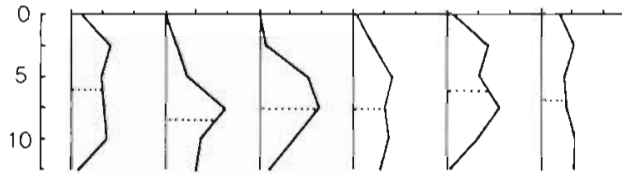

C1

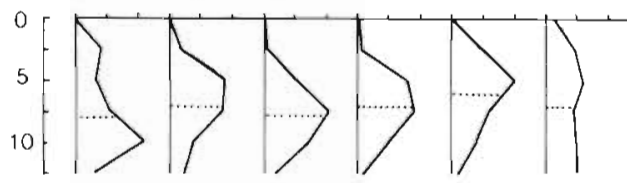

C5

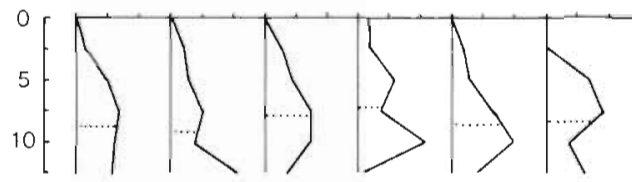

C69

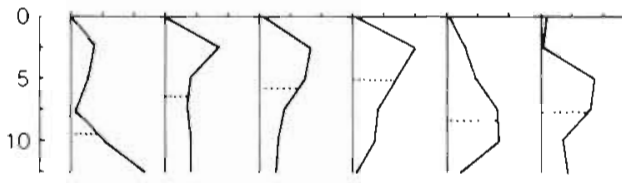

$\mathrm{C} 60^{\circ}$

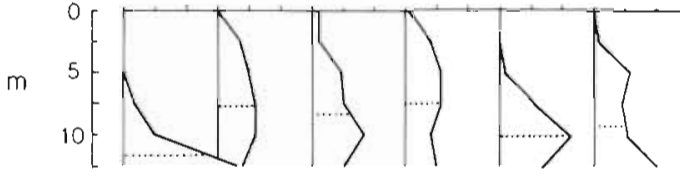

0

$100 \%$

Fig. 10. Acartia spp. Diel vertical distributions of given stages at Stn A on 29-30 Mar 1978. For further explanation see legend to Fig. 9

hand, N4 to 6 was located highest in the water column. There was no significant difference in the mean distribution depth between adult females and males. The ratio of ovigerous females among all adult females varied vertically and its vertical pattern changed irregularly from one month to the next.

Acartia N1 occurred exclusively in the bottom water even in April when all the other naupliar stages were most abundant at the surface (Fig. 6). The mean distribution depths of naupliar stages moved upwards with age through N6. Thereafter copepodites descended with age and the adult stage mainly occupied the bottom water except in March, when the mean distribution depth of $\mathrm{C} 2$ to $\mathrm{C} 6$ ascended after a sharp descent between $\mathrm{N} 6$ and $\mathrm{C} 1$. This ontogenetic change among the copepodites at Stn 5 in March is regarded as an exceptional case, because in this month the more usual descent of later copepodites was observed at the stations other than Stn 5 (Fig. 3b). A second anomalous distribution of Acartia was found in March; eggs occurred most abundantly at $5 \mathrm{~m}$ at $\operatorname{Stn} 5$, where adult females were almost entirely restricted to the surface layer. In April and May Acartia eggs were concentrated in the bottom water. The distribution of the floating eggs was correlated then with adult females rather than newly hatched nauplii in March.

Ontogenetic upward movement of Paracalanus nauplii ceased with N5 and the population gradually

Egg

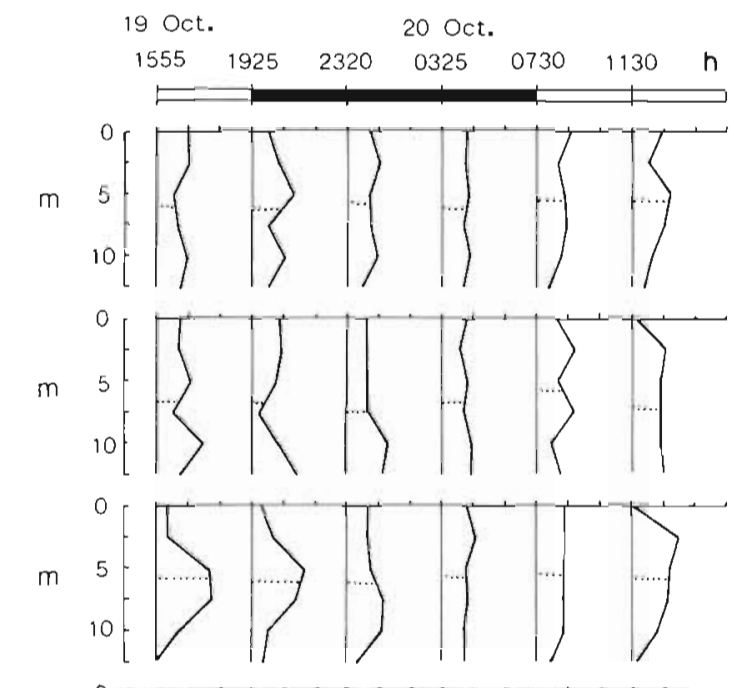

N1

C1

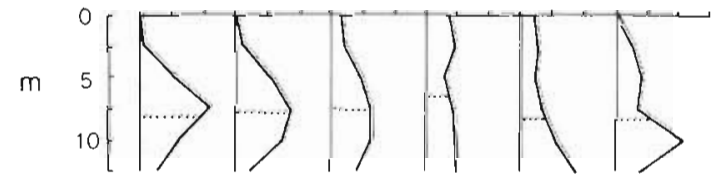

C5

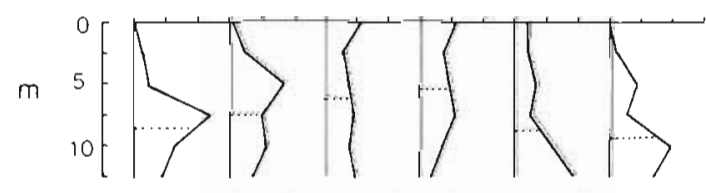

C6 \&

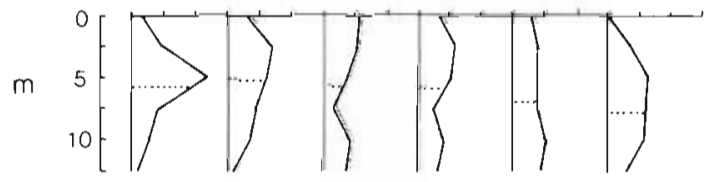

C6 $60^{\circ}$
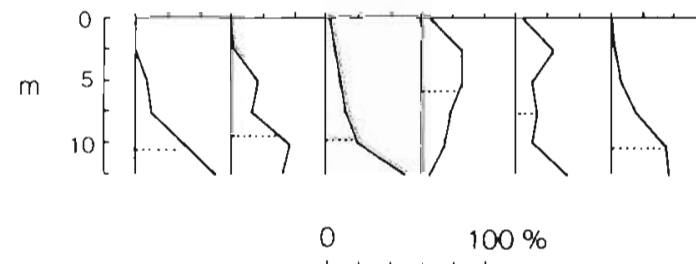

Fig. 11. Paracalanus crassirostris. Diel vertical distributions of given stages at Stn. A on 19-20 Oct 1978. For further explanation see legend to Fig. 9 
descended with age (Fig. 7). Differences in vertical distribution of the adult males and females were observed consistently throughout periods of high abundance. Eggs usually were most abundant in the surface layer and their distribution was more closely correlated with the distribution of $\mathrm{N} 1$ than with adult females.

\section{Diel vertical distribution}

On 29-30 March, a strong halocline occurred within the top $5 \mathrm{~m}$ at Stn A throughout the day and night (Fig. 8). Thermal stratification was apparent at $1725 \mathrm{~h}$ on 29 March but thereafter the temperature became relatively homogeneous due to night cooling of the surface water. In contrast, both temperature and salinity were nearly homogeneous throughout the water column on 19-20 October.

Diel patterns of vertical distribution of the dominant copepods during this period are shown in Fig. 9 to 11. On 29-30 March, Oithona davisae was generally concentrated in mid depth ( 5 to $10 \mathrm{~m}$ ) throughout the day and night, while on 19-20 October specimens were more evenly distributed at night and early in the morning (Fig. 9). Significant upward migration was observed only in late copepodite stages from 1725 to $2050 \mathrm{~h}$ in March and also from 1925 to $2320 \mathrm{~h}$ in October; they subsequently displayed slight midnight sinking. In this diel study ontogenetic changes of $O$. davisae, especially of the copepodites, during the daytime were obscure as compared with the monthly samples, and the pattern of the changes observed in the daytime completely disappeared at night.

A distinctive diel migration was found in adults of Acartia species (Fig. 10). Most adults were close to the bottom at $1725 \mathrm{~h}$ on 29 March. At the next sampling time $(2050 \mathrm{~h})$ they had dispersed upwards but not to the surface layer. Low salinities of the surface water on this date may have been responsible for this pattern. Lance (1962) has shown that upward nocturnal migration of some neritic copepods, including A. clausi, is limited by discontinuous salinity layers. Adult females displayed more extensive migration than adult males; Lance also indicated that males are less tolerant of dilute seawater than females. As noted above, the distribution of floating eggs was correlated with that of adult females, i.e. the depth of the greatest abundance of eggs changed from the bottom layer $(12.5 \mathrm{~m})$ at $1725 \mathrm{~h}$ to the $2.5 \mathrm{~m}$ layer at $2050 \mathrm{~h}$ as did that of adult females. N1 was restricted to the bottom layer throughout the day and night. Late naupliar stages descended slightly from 1725 to $2050 \mathrm{~h}$, while late immature copepodites gradually ascended from 2050 to $0430 \mathrm{~h}$. Consequently the patterns of ontogenetic changes observed in the daytime were obscured during the night.

Paracalanus crassirostris was relatively evenly distributed from midnight to early morning on 19-20 October (Fig. 11). Among all the developmental stages, only adult males displayed an extensive upward migration from 2320 to $0325 \mathrm{~h}$. Because of this midnight migration, the mean distribution depth of adult males became equal to that of females at $0325 \mathrm{~h}_{\text {; }}$ at other sampling times males were distributed deeper than females. Late immature copepodite stages underwent less extensive upward migration during the night, but the other stages, including eggs and adult females, showed no noticeable diel vertical change. Ontogenetic changes in vertical distribution of this species were relatively obscure in the daytime on both 19 and 20 October, and at night changes were not detectable.

\section{DISCUSSION}

Although vertical distribution of neritic copepods, especially nauplii, has not been extensively studied, previous work has suggested that they are generally distributed in the surface water during naupliar stages and change their depth habitat to deeper layers after metamorphosis. However, these studies do not appear to have correctly described the distribution of early naupliar stages, because the nets used had too large mesh openings to collect them and/or because naupliar instars were not distinguished stage by stage. Carter (1965) investigated vertical distribution of Pseudocalanus minutus Krøyer in a small bay in the near-arctic of northern Labrador, Canada, and found that nauplii were concentrated largely in the surface water while copepodites were evenly scattered in mid layers. Furuhashi (1976) reported that in Maizuru Bay, copepod nauplii generally inhabited the surface layer independent of the distribution of copepodites. Landry (1978) described ontogenetic vertical distribution of Acartia clausi in a shallow marine lagoon, Puget Sound, USA, in which nauplii aggregated in the surface water throughout the day and night while copepodites were centered in the deeper water during the day and migrated toward the surface at night. More recently, Sekiguchi (1985) studied ontogenetic vertical distributions of neritic copepods, including the distribution of their floating eggs, in Ise Bay on the Pacific coast of central Japan. Eggs and nauplii of the dominant calanoid copepods $A$. clausi, Calanus sinicus Brodsky and Paracalanus parvus (Claus) in the bay were largely found in surface layers, their adults in water close to the bottom, and young copepodites in the intermediate layers. The results of the present study indicate that during the daytime copepods are 
usually distributed in relatively deep layers in early naupliar stages and are found further upward with age until late naupliar or early copepodite stages. This upward ontogenetic change during the naupliar stages and descent of copepodites were consistent for the dominant calanoid and cyclopoid copepods studied here, suggesting that this pattern of ontogenetic change is widespread among neritic planktonic copepods.

Details of ontogenetic distributions depend on the species. The vertical distribution of Paracalanus crassirostris $\mathrm{N} 1$ was similar to their floating eggs, which were concentrated in the surface layer at times when adult females were more abundant at the middepth. This suggests that most eggs of this species may continue to drift until hatching. In contrast, most Acartia N1 were always distributed close to the bottom independent of the distribution of floating eggs. The aggregation of $\mathrm{N} 1$ at the bottom may result from sinking of eggs after spawning and hatching from the sediment, although it also appears that some of the nauplii can hatch from floating eggs (Ueda 1981). Sinking rate of $A$. clausi eggs was experimentally measured as $3 \mathrm{~m} \mathrm{~h}^{-1}$ by Landry (1978) and $1.28 \mathrm{~m} \mathrm{~h}^{-1}$ by Uye (1980). The similarity in diel vertical distribution between Acartia eggs and adult females suggests that most of the eggs were spawned within the period of each preceding sampling interval $(<4 \mathrm{~h})$, and supports a conclusion of continuous, day-and-night spawning of Acartia species (Uye 1981). A further difference between Acartia and P. crassirostris is found in the stage occupying the most upper layer in the day: usually N6 for Acartia and N5 for P. crassirostris.

Furuhashi (1976) studied diel vertical migration of dominant copepods in Maizuru Bay. Despite sampling differences between his study and ours, similar results were obtained. First, adults of all the species, except for Paracalanus crassirostris females in the present study, exhibited upward nocturnal migration. Second, Acartia displayed the most extensive migration among the dominant copepods. Third, adult females of $P$. crassirostris were usually much more abundant in the surface water than adult males during the day, but the males migrated upwards more extensively in the period from midnight to early morning when the sex ratio in the surface water became close to unity. Since this distributional coincidence between females and males after midnight enhances the encounter probability between them, diurnal migration may initiate mating behavior in the $P$. crassirostris population. These common results of the 2 studies are regarded as gen- eral features of diel vertical migration and distribution of these neritic copepods.

Acknowledgements. I thank the staff of the Fisheries Research Station, Kyoto University, for help during this work. Sampling for the diel study was kindly assisted by Dr. $H$. Nakahara, Dr T Minami, Mr. H. Yokoyama and Mr. K. Maekawa. I am also grateful to Dr. F. D. Ferrari of the Smithsonian Institution for correcting the manuscript.

\section{LITERATURE CITED}

Banse, K. (1964). On the vertical distribution of zooplankton in the sea. Prog. Oceanogr. 2: 55-125

Carter, J. C. H. (1965). The ecology of the calanoid copepod Pseudocalanus minutus Krøyer in Tessiarsuk, a coastal meromictic lake of northern Labrador. Limnol. Oceanogr. 10: 345-353

Furuhashi, K. (1976). Diel vertical migration suspected in some copepods and chaetognaths in the inlet waters, with a special reference to behavioural differences between male and female, noted in the former. Publs Seto mar. biol. Lab. 22: 355-370

Lance, J. (1962). Effects of water of reduced salinity on the vertical migration of zooplankton. J. mar. biol. Ass. U.K. 42: 131-154

Landry, M. R. (1978). Population dynamics and production of a planktonic marine copepod, Acartia clausii, in a small temperate lagoon on San Juan Island, Washington. Int. Revue ges. Hydrobiol. 63: 77-119

Sekiguchi, H. (1975). Seasonal and ontogenetic vertical migrations in some common copepods in the northern region of the North Pacific. Bull. Fac. Fish. Mie Univ. 2: 29-38

Sekiguchi, H. (1985). Biology of cladocerans and copepods in Ise Bay. 2. Vertical distribution of neritic copepods in relation to their life histories. Bull. Fac. Fish. Mie Univ. 12 : 1-12

Ueda, H. (1981). Hatching time of Acartia clausi (Copepoda) eggs isolated from the seawater in Maizuru Bay. Bull. Plankton Soc. Japan 28: 13-17

Ueda, H. (1986). Taxonomic reexamination and geographic distribution of copepods known as Acartia clausi in Japanese coastal and inlet waters. J. oceanogr. Soc. Japan 42: 134-138. (In Japanese; English abstract)

Ueda, $H$. (in press). Temporal and spatial distribution of the two closely related Acartia species A. omorii and A. hudsonica (Copepoda, Calanoida) in a small inlet water of Japan. Estuar. coast. Shelf Sci.

Uye, S. (1980). Development of neritic copepods Acartia clausi and A. steuen I. Some environmental factors affecting egg development and the nature of resting eggs. Bull. Plankton Soc. Japan 27: 1-9

Uye, S. (1981). Fecundity studies of neritic calanoid copepods Acartia clausi Giesbrecht and $A$. steueri Smirnov: a simple empirical model of daily egg production. J. exp. mar. Biol. Ecol. 50: 255-271

Williams, R., Conway, D. V. P. (1984). Vertical distribution, and seasonal and diurnal migration of Calanus helgolandicus in the Celtic Sea. Mar. Biol. 79: 63-73 